\title{
La arbitrabilidad del daño moral
}

\author{
Luis Parraguez Ruiz* \\ Juan Carlos Darquea** \\ Recibido/Received: 27/06/2017 \\ Aceptado/Accepted: 21/07/2017
}

SUMARIO: 1. Introducción. 2. La reparabilidad del daño moral en sede de responsabilidad contractual. 3. La transigibilidad como requisito previsto por la Ley de Arbitraje y Mediación. 4. La reparación del daño moral en el derecho nacional y el artículo 1572 del Código civil. Un caso de errónea interpretación. 4.1 Desarrollo de la jurisprudencia ecuatoriana sobre la reparación del daño moral en la responsabilidad contractual. 4.2 Desarrollo de laudos nacionales e internacionales sobre la reparación del daño moral en la responsabilidad contractual. 5. Arbitrabilidad del daño moral en materia de responsabilidad extracontractual. 6. Conclusión.

PALABRAS CLAVE: arbitrabilidad objetiva, transigibilidad, daño moral, responsabilidad contractual.

KEYWORDS: objective arbitrability, arbitrability, moral damage, contractual liability.

RESUMEN: El presente artículo analiza si en el derecho ecuatoriano el daño moral puede ser materia de arbitraje.

* Profesor titular de Derecho civil del Colegio de Jurisprudencia de la Universidad San Francisco de Quito y árbitro de derecho de los Centros de Arbitraje y Mediación de la Cámara de Comercio de Quito y de la Cámara de Comercio Ecuatoriano Americana. Licenciado en Ciencias Sociales y Jurídicas por la Universidad de Chile, Abogado por la Corte Suprema de Chile, Doctor por la Universidad de Salamanca en Derecho Privado.

** Asociado en FERRERE Ecuador y Profesor adjunto de Derecho civil del Colegio de Jurisprudencia de la Universidad San Francisco de Quito. Abogado por la Universidad San Francisco de Quito.

L. Parraguez y J.C. Darquea, "La arbitrabilidad del daño moral”, Revista Ecuatoriana de Arbitraje, No. 8, 2016. 
Para ello, se parte del análisis de legislación comparada respecto de la reparabilidad del daño moral en sede contractual, así como de la transigibilidad de este tipo de daños. Luego, se analiza la normativa local, para concluir que, ya sea en sede contractual o extracontractual, los daños morales son plenamente resarcibles. Asimismo, al ser derechos transigibles, estos podrían ser sometidos a arbitraje.

\begin{abstract}
This article analyzes whether moral damages can be subject to arbitration. For this purpose, this article conducts a comparative analysis regarding the possibility of moral damages being awarded under a contractual claim, as well as the arbitrability of these type of claims. Finally, by means of a domestic law analysis it concludes that both, contractual and non-contractual moral damage claims are viable; hence, they can be submitted to arbitration.
\end{abstract}

\title{
1. INTRODUCCIÓN
}

Un principio fundamental e indiscutido en materia arbitral es el de kompetenz, según el cual el tribunal arbitral tiene competencia para decidir sobre su propia competencia ${ }^{1}$. Para poder declararse competente, el tribunal deberá determinar si se cumplen los requisitos subjetivos y objetivos previstos por la ley. En otras palabras, deberá verificar si existe arbitrabilidad subjetiva y objetiva.

No es tema del presente trabajo la arbitrabilidad subjetiva, que está relacionada de los sujetos capaces de brindar su consentimiento para someterse a arbitraje. Nuestra atención se centra en la arbitrabilidad objetiva que da cuenta de la clase de controversias que "pueden resolverse por arbitraje y cuáles quedan relegadas exclusivamente al dominio de los tribunales de Justicia naciona-

1. Este principio ha sido expresamente previsto en el Art. 22 de la Ley de Arbitraje y Mediación que en su sección pertinente establece: "Una vez constituido el tribunal, se fijará día y hora para la audiencia de sustanciación en la que se posesionará el secretario designado, se leerá el documento que contenga el convenio arbitral y el tribunal resolverá sobre su propia competencia”. 
les"'2. Se trata, por consiguiente, de una decisión de carácter legislativo que queda entregada a la discrecionalidad de cada Estado para decidir qué asuntos pueden resolverse mediante arbitraje, a la luz de sus planes políticos, sociales y económicos ${ }^{3}$. Es así que, en último término, la arbitrabilidad del daño moral que nos ocupa, depende de la regulación de cada Estado. En el presente trabajo nos proponemos demostrar que en nuestro ordenamiento civil, una vez despejadas ciertas confusiones, esta modalidad de daño es perfectamente arbitrable.

Ahora bien, esa arbitrabilidad está estrechamente ligada a un tema más general y poco pacífico, que constituye su soporte dogmático, como es la posibilidad de incardinar el daño moral en la responsabilidad contractual. Es un debate abierto en la doctrina y jurisprudencia que, en el caso particular del Ecuador, se encuentra estimulado por una norma medular que, merced a una errada lectura, repetida sacramentalmente por la rutina, esa vieja enemiga de la ciencia, ha hecho más opaco el panorama.

Por ello comenzaremos el presente trabajo demostrando que la indemnización del daño moral en materia contractual es una cuestión que, cabalgando sobre fundamentales principios del derecho, ha superado las primitivas reticencias y objeciones para instalarse con creciente fuerza en la doctrina universal y, lo que nos interesa, en los ordenamientos que integran la familia que comparte el Código civil de Bello. Examinaremos luego la situación particular de esta reparación en el derecho nacional para concluir con el examen de su arbitrabilidad a la luz de la Ley de Arbitraje y Mediación de nuestro país.

2. A. REDFERN et al, Teoría y práctica del arbitraje comercial internacional. Adaptada por N. MARIGO y F. OsSA. 4ta Ed., La Ley, 2007, p. 227.

3. Ídem, p. 228. 


\section{LA REPARABILIDAD DEL DAÑO MORAL EN SEDE DE RESPONSABILIDAD CONTRACTUAL}

El marco de comparación para este primer análisis, ya se lo anticipó, está delimitado por aquellos ordenamientos que integran una misma familia civil con el ecuatoriano, sea porque constituyen su antecedente matricial, como es el derecho civil francés, o se han nutrido de esa misma fuente, como el español o, finalmente, han adoptado el mismo Código, como el chileno y el colombiano. Con excepción del derecho nacional, todos ellos comparten la circunstancia de no haber regulado la indemnización del daño moral en sus códigos civiles, pero cuentan, en cambio, con una doctrina y jurisprudencia que han hecho importantes progresos en la materia.

JOSSERAND comentaba la posición tradicional de la jurisprudencia francesa de su época, que limitaba la responsabilidad contractual al daño material, lo que no llama mucho la atención pues tal era la doctrina de DOMAT y POTHIER, y se tenía como cierto que esa era la dirección que apuntaba el espíritu de la legislación francesa $^{4}$. Contrario a esa tesis reductora el maestro de Lyon expresaba su esperanza, muy próxima a la convicción, de un cambio de tendencia en los tribunales franceses:

[Que] llegue a evolucionar en sentido liberal y que el daño moral sea tomado en consideración para la determinación de la indemnización contractual", pues los textos legales "no hacen distinción ni existe una buena razón para distinguir en este aspecto (...) Así se comprende que en la actualidad la doctrina se pronuncie en dicho sentido, como también el derecho comparado, en general ${ }^{5}$.

También MAZEAUD y TunC observaron que "[l]os preceptos del Código civil francés están concebidos en términos por demás amplios" como para permitir la reparación del daño moral en la

4. H. Mazeaud, L. Mazeaud y A. Tunc, Tratado de la responsabilidad civil, Tomo primero, Vol. I, Ed. E.J.E.A., 1977, p. 433.

5. L. Josserand, Derecho civil, Tomo II, Vol. I, Ed. Ediciones jurídicas Europa-América, 1950, p. 509. 
responsabilidad contractual ${ }^{6}$ y citan numerosos fallos de los tribunales franceses que ordenaron su indemnización ${ }^{7}$. En efecto, el artículo 1146 del antiguo Code mostraba la amplitud conceptual a la que se refieren los MAZEAUD, limitada solamente por la previsibilidad de los daños y perjuicios a que se refería el artículo 1150 (qui ont été prévis ou qu’on a pu prevoir).

Como lo previó JOSSERAND, la jurisprudencia francesa continuó avanzando en la admisibilidad del daño moral en materia de responsabilidad contractual, no así el legislador que en su reforma de 2016 al derecho de las obligaciones y del contrato, que incorporó mucha doctrina jurisprudencial, no lo tomó en cuenta. Es más, fue dejada de lado una norma sobre perjuicio extrapatrimonial que constaba en el llamado Anteproyecto Catalá, según la cual "es reparable todo perjuicio cierto consistente en la lesión de un interés lícito, patrimonial o extrapatrimonial, individual o colectivo" (artículo 1343 del proyecto).

Entre los autores españoles, CASTÁN TOBEÑAS, luego de resaltar que el tema es polémico y que la tendencia era negativa en la doctrina más antigua, considera que "es de justicia la reparación o compensación de los daños morales, ya pueda encuadrarse dentro de las normas legales de la indemnización de daños y perjuicios, o ya se acoja, en cuanto ésta no sea aplicable, a los principios generales del Derecho" ${ }^{8}$ y agrega que "[e]n la doctrina española puede decirse que, actualmente, está unánimemente aceptada la indemnización por daño moral en el incumplimiento contractual" ${ }^{\prime \prime}$. En similar sentido se pronuncia DíEz-PicAzo respecto de la doctrina tradicional adversa a esta indemnización, destacando luego que"[1]a jurisprudencia más reciente, sin embargo, se inclina a un posible resarcimiento de los daños morales contractua-

6. H. Mazeaud, L. Mazeaud y A. Tunc, N. 4, p. 465.

7. Ídem, pp. 468-470. Entre otros, la indemnización por incumplimiento de una convención relativa a un bien sin valor patrimonial, como un retrato de familia; o el que afecta las convicciones religiosas de la contraparte; o de quien debía renovar una concesión funeraria y no lo hizo lo que impidió a los padres conocer donde se encuentran los restos de su hijo; del transportista cuya negligencia impidió que un pasajero llegara a tiempo a un funeral; del empresario que ejecuta una obra de manera defectuosa por el perjuicio moral que le causa al autor, etc.

8. J. Castán Tobeñas, Derecho civil español común y foral, Tomo 3, Ed. Reus S.A., 2008, p. 283.

9. Ídem, nota al pie 504, p. 282. 
les", para sostener finalmente que "[n]o puede excluirse la indemnización de los daños morales por el hecho de que la relación entre las partes sea de naturaleza contractual" ${ }^{\prime 10}$.

En su artículo Daños morales derivados del incumplimiento ${ }^{11}$, Antonia Nieto AlOnso se apoya en el artículo 1101 del Código civil español "que proporciona al acreedor una acción para ser resarcido de los daños y perjuicios que el incumplimiento del contrato le ha causado -responsabilidad contractual-se refiere in genere, a la "indemnización de daños y perjuicios", para derivar de allí que "en principio, no deberían excluirse los daños morales". Para reforzar su aserto acude a la sentencia de 28 de marzo de 2005 del Tribunal Supremo de España (RJ 2005/2614) que "parte del incumplimiento contractual y la responsabilidad que se deriva (art. $1101 \mathrm{CC}$ ) que comprende la indemnización por los daños morales". Más reciente, CARRASCO PERERA vuelve sobre la idea de que:

la indemnización del daño moral derivado del incumplimiento contractual no es puesta hoy en duda por la jurisprudencia", aunque denuncia la ambivalencia del término "daño moral" en el lenguaje jurídico español y en la cual se ha venido moviendo la jurisprudencia de ese país ${ }^{12}$.

En la doctrina chilena ALESSANDRI, SOMARRIVA, VODANOVIC y RODRÍGUEZ GREZ sostienen y demuestran la indemnizabilidad del daño moral teniendo como argumento central el principio de la reparación integral y las circunstancias de que la ley la ha omitido pero no excluido ${ }^{13}$; y DIEZ SCHWERTER la fundamenta en disposiciones constitucionales que la hacen viable y que, como se verá de inmediato, fueron también invocadas por alguna jurisprudencia ${ }^{14}$.

10. L. DíEz-Picazo, Fundamentos de Derecho civil patrimonial, Tomo II, 6ta Ed., Ed. Thomson-Civitas, 2008, p. 793.

11. Anuario de Derecho civil, Tomo LIX, Fascículo III, julio-septiembre 2006, p. 1119.

12. Á. Carrasco Perera, Derecho de contratos, 1ra Ed., Ed. Thomson Reuters, 2010, p. 1230.

13. A. Alessandri, M. Somarriva y A. Vodanovic, Tratado de las obligaciones, Tomo segundo, Ediciones EJS, 2016, pp. 296 y ss.; P. RodRíGUEZ, Responsabilidad contractual, Ed. Jurídica de Chile, 2015, pp. 232 y ss.

14. J. L. Diez Schwerter, El daño extracontractual, Ed. Jurídica de Chile, 1997, p. 104. 
OSPINA FeRnÁNDEZ, en Colombia, cuestiona la doctrina que excluye el daño moral de la responsabilidad contractual argumentando que:

La doctrina moderna ha reaccionado con la precitada tesis, por carecer ella de todo fundamento racional (...) la equidad reclama con igual vigor la indemnización del perjuicio moral en el campo extracontractual y en el contractual. La víctima de un hecho ilícito siempre tiene derecho a que se le reparen todos los daños que se le hayan causado (nema ex alteria culpa praegravari debet) y este máximo postulado de justicia no admite distingo, porque ese hecho ilícito consiste en la violación de un contrato o en el quebranto de deberes emanados de otras fuentes ${ }^{15}$.

En el mismo sentido opina DURÁN TRUJILLO quien pone de relieve, que "la inejecución de todo contrato reporta desasosiego, contrariedad, inquietud en la parte burlada, máxime cuando el contrato se refiere a aquellas cosas que tienen valor de afección para el contratante"16.

La jurisprudencia chilena no ha sido uniforme en esta materia. Las sentencias de 13 de agosto de 1935, 2 de diciembre de 1948 de la Corte de Santiago y de 27 de agosto de 1990 de la Corte Suprema de Chile excluyeron categóricamente la indemnización del daño moral en la responsabilidad derivada del incumplimiento del contrato. El argumento de la sentencia mencionada de la Corte Suprema fue que "según el artículo 1556 del Código Civil la indemnización proveniente del hecho de no haberse cumplido la obligación, o de haberse cumplido imperfectamente, o de haberse retardado su cumplimiento, sólo comprende el año emergente y el lucro cesante" ${ }^{17}$. En su sentencia de 22 de marzo de 2006 la Corte Suprema insistió en que "el artículo 2329 del Código civil que admite la reparación del daño moral en materia delictual, no lo hace extensible a la responsabilidad originada en la falta de cumplimiento de los contratos" y que "[e]n consecuencia, los tér-

15. G. Ospina Fernández, Régimen General de las Obligaciones, Ed. Temis, 2008, pp. 122 y 123.

16. R. DurÁn Trujillo, Nociones de responsabilidad civil, Ed. Temis, 1957, p. 89.

17. Corte Suprema de Justicia de Chile. Sentencia, 27/08/1990. Citado en Repertorio de legislación y jurisprudencia chilenas, Tomo V, 3ra Ed. actualizada, Ed. Jurídica de Chile, 1997, p. 355. 
minos del artículo citado (1556 del Código civil chileno) como quiera que aluden a conceptos patrimoniales, permiten afirmar que nuestro Derecho positivo no contempla en materia contractual la indemnización judicial del daño"18.

Sin embargo, el 3 de julio de 1951 la misma Corte se pronunció por la tesis contraria y sostuvo que "[e]l daño moral es también indemnizable dentro del incumplimiento de una obligación contractual cuando se produce por culpa del deudor, pues la ley positiva no hace ninguna distinción al respecto entre daño material y daño moral, tanto más cuanto que ambos tienen una misma causa, aunque efectos diferentes". Por su parte, la sentencia de 20 de octubre de 1994 se basó en la garantía constitucional a la integridad física y síquica, para concluir que "esta última, como en el caso de autos, puede verse trastornada, precisamente, por la falta en que uno de los contratantes incurrió frente a los deberes que le imponía el contrato". La doctrina de la sentencia de 1951 fue reiterada en la de 20 de octubre de 1994 en la que se dijo que la distinción que hace el artículo 1556 entre daño emergente y lucro cesante "no excluye de un modo forzoso la reparación del daño meramente moral"19, y en el fallo de 14 de abril de 1954 que admitió la indemnización del daño moral proveniente del incumplimiento de un contrato de transporte ${ }^{20}$. El 9 de julio de 2007 la Corte de Rancagua hizo una interesante consideración sobre esta materia y dijo que:

Las nuevas concepciones que sobre el resarcimiento del daño moral derivado del incumplimiento de contratos se impone en el derecho actual, según ha señalado la jurisprudencia de nuestros tribunales, que ha determinado que el concepto de daño emergente que emplea la norma del artículo 1556 del Código Civil, comprende no sólo el daño pecuniario sino también el extrapatrimonial o moral (...). Procede entonces en la responsabilidad contractual la reparación del daño extrapatrimonial, cuando se encuentra ligado a un daño material y, si como sucede en la especie, se trata de un daño moral puro

18. Corte Suprema de Justicia de Chile. Sentencia, 22/03/2006. Citado en Jurisprudencia al día, Anuario 2006, Tomo II (Derecho privado), Ed. Lexis Nexis, 2007, p. 7.

19. Corte Suprema de Justicia de Chile. Sentencia 20/10/1994, N. 17, p. 356.

20. Ídem, p. 357. 
que tenga un nexo causal con el incumplimiento contractual, y que el deudor, al incumplir su obligación haya podido preverlo $^{21}$.

El 12 de julio de 1994 la Corte Suprema de Colombia, "siguiendo la doctrina universal en el punto", se pronunció sobre la procedencia, aunque calificada de excepcional, de indemnizar el daño moral, ocasionado al paciente por el incumplimiento del servicio médico profesional. Se dijo entonces que, como consecuencia de los daños materiales ocasionados por el incumplimiento, "se producen de manera autónoma, de manera independiente, dolores, padecimientos, aflicciones y afectaciones como individuo y ser social, todos ellos constitutivos de lo que se denomina el daño moral, evento en el cual deberá indemnizarse" ${ }^{\prime 22}$.

\section{LA TRANSIGIBILIDAD COMO REQUISITO PREVISTO POR LA Ley de Arbitraje y Mediación}

Ya se dijo que la arbitrabilidad objetiva es una cuestión que depende de la legislación interna de cada Estado. En Ecuador se encuentra regida por la Ley de Arbitraje y Mediación, ${ }^{23}$ cuyo artículo 1 prescribe:

Art. 1.- El sistema arbitral es un mecanismo alternativo de solución de conflictos al cual las partes pueden someter de mutuo acuerdo, las controversias susceptibles de transacción, existentes o futuras para que sean resueltas por los tribunales de arbitraje administrado o por árbitros independientes que se conformaren para conocer dichas controversias (énfasis añadido).

21. Corte de Rancagua. Sentencia, 9/07/2007. Citado en Jurisprudencia al día, Anuario 2007, Tomo II (Derecho privado), Ed. Lexis Nexis, 2008, p. 111.

22. Corte Suprema de Colombia. Sentencia, 12/07/1994. Citado en Contreras Restrepo et al, Código civil comentado. Ed. Leyer, 2006, p. 1046.

23. Ley de Arbitraje y Mediación, Codificación publicada en el RO No. 417, 14/12/2006. 
Del texto transcrito aparece claro que el núcleo de la arbitrabilidad en nuestro país es la posibilidad de transigir respecto de la materia que debe ser resuelta, lo que nos remite a las normas sobre el contrato de transacción contenidas en el Código civil, definido en su artículo 2348 como aquel en que "las partes terminan extrajudicialmente un litigio pendiente, o precaven un litigio eventual". Descrito de esta manera su objeto, el Código no contiene una construcción genérica que permita identificar la plenitud de los asuntos, actual o potencialmente litigiosas, sobre los que puede transarse. Su método ha sido más bien señalar aquellas materias que no son transigibles, como el estado civil de las personas, la acción penal, los alimentos futuros (sin aprobación judicial), los derechos ajenos y los derechos inexistentes ${ }^{24}$. Esta casuística nos permite entender, entonces, que es materia transigible todo aquello que no ha sido calificado como no transigible por la ley, en virtud de lo dispuesto por el artículo 8 del Código civil, según el cual “[a] nadie puede impedirse la acción que no esté prohibida por la ley".

A nivel doctrinario y jurisprudencial la materia transigible se ha relacionado comúnmente con el carácter patrimonial del derecho objeto de transacción, como lo advierte el profesor VALDÉs SÁNCHEZ:

[...] la materia incluida legalmente en la transacción está representada por todos aquellos bienes y servicios, de contenido patrimonial, sobre los cuales las partes están en capacidad legal de celebrar el acuerdo transaccional, bienes y servicios éstos cuya existencia e intercambio no deben ser contrarios a la ley, al derecho público de la Nación, ni a las buenas costumbres ${ }^{25}$.

Es en este punto donde aparece el primer obstáculo puesto a la arbitrabilidad del daño moral, toda vez que este afecta a un derecho o bien jurídico de naturaleza extrapatrimonial, como el

24. Al respecto véase, Art. 2351 "La transacción puede recaer sobre la acción civil que nace de delito; pero sin perjuicio de la acción penal"; Art. 2352 "No se puede transigir sobre el estado civil de las personas"; y, Art. 2354 "No vale la transacción sobre derechos ajenos o sobre derechos que no existen" del Código civil.

25. R. VALDÉS SÁNCHEZ, La transacción: solución alternativa de conflictos, Legis, 1997, p. 110. 
honor, la privacidad, el buen nombre, entre otros. Supuesto que por esta razón no es asunto transigible, se concluye equivocadamente que tampoco podría ser materia de arbitraje.

Hay por lo menos tres razones que hacen inaceptable esa tesis. En primer lugar, la ley no limita el objeto del contrato de transacción a los bienes y derechos de contenido patrimonial; en segundo lugar, la indemnización del daño moral, al menos en la forma prevista por nuestra legislación, siempre se concreta en una indemnización de carácter pecuniario; $\mathrm{y}$, por último, algunas especies de daños morales tienen un componente económico que los asimila a los daños patrimoniales.

En relación con el primer motivo, la circunstancia de que generalmente los derechos patrimoniales son susceptibles de transacción, no autoriza a vincular la transacción con la patrimonialidad de la materia, porque lo esencial de aquella es que se refiera a asuntos relacionados con el interés privado de quienes celebran el contrato, sin afectar los derechos o intereses de terceros. Al efecto escribe LARREA HOLGUín:

No todos los derechos pueden ser objeto de transacción, sino sólo aquellos que tengan un carácter privado, pues, como dice De Buen, la transacción no debe servir nunca para eludir el cumplimiento de las leyes ni para la renuncia de derechos irrenunciables. En consecuencia: a) Si bien se puede transigir sobre la acción civil procedente de un delito, no por eso se extinguirá la acción pública para la imposición de la pena correspondiente $[\ldots]^{26}$ (énfasis añadido).

Si se toma en cuenta el carácter privado del derecho o bien jurídico protegido como principal característica para determinar la materia transigible, pueden incluirse una serie de derechos que, sin ser patrimoniales, no afectan derechos ajenos o del orden público, y podrían, por lo mismo, ser objeto de un contrato de transacción.

26. J. Larrea Holguín, Derecho Civil del Ecuador, Tomo XIV, Contratos: Préstamos, Garantías, Depósitos, Transacción, Aleatorios, 1ra Ed., Corporación de Estudios y Publicaciones, 2002, p. 359. 
En cuanto al segundo motivo expuesto, tratándose del daño moral, nuestra legislación ha seguido la tendencia generalizada en derecho comparado de conceder una indemnización pecuniaria y no una reparación in natura, debido a la dificultad, cuando no imposibilidad, que implica volver las cosas al estado anterior al hecho que ocasionó el daño. De esta manera, la indemnización no busca restablecer el patrimonio del afectado ni reconstituir el equilibrio emocional lesionado. La indemnización pecuniaria "no cumple una función valorativa exacta, el dolor no puede medirse o tasarse, sino que se trata solamente de dar algunos medios de satisfacción, lo cual no es igual a equivalencia"27. Por ello el artículo 2232 del Código civil entrega la fijación del quantum indemnizatorio del daño moral a la prudencia del juzgador ${ }^{28}$. Por consiguiente, a pesar de que se cause una lesión a un derecho extrapatrimonial, regularmente la indemnización será de naturaleza patrimonial, de modo que nada obsta para que el asunto sea transigible, lo que a su vez lleva de la mano a la posibilidad de someterlo a arbitraje.

Por último, si bien el daño moral per se, el llamado pretium dolori $^{29}$, es el daño extrapatrimonial por excelencia, existe una categoría de daños extrapatrimoniales más amplia, algunos de los cuales tienen un tinte de patrimonialidad. Tal es el caso de los llamados daños morales objetivados, es decir, aquellos que por su misma naturaleza son susceptibles "de concretarse probatoriamente en perjuicios patrimoniales" 30 . En este tipo de daños, la lesión a un derecho o bien jurídico extrapatrimonial

27. CNCiv. Ferraiolo, Enrique A. c/ EDENOR SA y ot., Sala E, 6-9-2000, E.D. 2003-1-318. Citado por C. PARELlADA, "El daño moral. La evolución el pensamiento en el derecho argentino", Responsabilidad civil, A. Kemelmajer de Carlucci (Dir), Rubinzal-Culzoni Editores, 2007, p. 362. En el mismo sentido véase, J. LóPEz, Perjuicios morales, Ediciones Doctrina y Ley Ltda, 1997, pp. 15-16.

28. El Art. 2232 del Código civil prescribe: “[...] La reparación por daños morales puede ser demandada si tales daños son el resultado próximo de la acción u omisión ilícita del demandado, quedando a la prudencia del juez la determinación del valor de la indemnización atentas las circunstancias, previstas en el inciso primero de este artículo" (énfasis añadido).

29. El pretium doloris incluye dos componentes. Comprende, en primer lugar, el dolor físico que sufre la víctima como consecuencia del hecho dañoso; en segundo lugar, comprende puro daño moral, reflejado en la pena, la tristeza y el sufrimiento (no físico). Al respecto véase, J. MAYO, "El daño moral. Los diversos supuestos característicos que lo integran", Revista de Derecho de Daños. Daño moral, Buenos Aires: Rubinzal-Culzoni Editores, 2001, pp. 179-183.

30. C.S.J., sala de neg. Gen., 5/11/1942, “G.J.”, Tomo LVI, p. 487. Citado por J. TAMAYo JARAmiLlo, Tratado de responsabilidad civil, Tomo II, Legis Editores S.A., 2008, p. 534. 
tiene repercusiones patrimoniales, como sucede con las pérdidas económicas que sufre un comerciante como consecuencia de una lesión a su reputación comercial, materia que, con mayor razón, resulta perfectamente arbitrable.

En conclusión, el principal requisito que la Ley de Arbitraje y Mediación prevé para que una controversia sea sometida a arbitraje se cumple en el caso que nos ocupa, pues el daño moral es transigible, en tanto asunto que atañe únicamente a la persona que lo ha sufrido, a lo que suma el hecho de que nuestra legislación prevé una indemnización pecuniaria sobre la cual se puede negociar libremente.

\section{LA REPARACIÓN DEL DAÑO MORAL EN EL DERECHO NACIONAL Y EL ARTÍCUlO 1572 DEL Código CIVIL. UN CASO DE ERRÓNEA INTERPRETACIÓN}

El artículo 5 de la Ley de Arbitraje y Mediación contempla la posibilidad de que se celebre un convenio arbitral antes de que surja una controversia, lo que nos habla claramente de una disputa contractual, o una vez que ella se ha producido, caso en el cual la contienda puede ser contractual o extracontractual. Por ello, es necesario hacer un análisis de nuestra legislación para concluir que esta permite la reparación del daño moral en sede contractual, y que, por ende, puede ser sometido a arbitraje.

Las normas relativas a la reparación del daño moral se encuentran en el Título XXXIII del Libro IV del Código civil, relativo a los delitos y cuasidelitos, lo que ha llevado a pensar a un importante sector del foro y de la academia que la indemnización de este tipo de daño únicamente puede darse en sede de responsabilidad extracontractual.

No obstante, bien entendido el principio capital de la responsabilidad civil sobre la reparación integral del daño, que implica restablecer al afectado al estado en que se encontraba antes de 
producirse aquél, contiene la exigencia de que se repare su esfera patrimonial tan bien como la extrapatrimonial. Plantear en esta materia un tratamiento distinto para la responsabilidad contractual y la extracontractual, lleva a extremos ilógicos, como lo hizo notar la Corte Suprema de Chile en su sentencia de 5 de septiembre de 2001:

[...] conduce a situaciones absurdas, como sucede en los casos de responsabilidad profesional médica, en que no resulta equitativo que si no existe vínculo contractual entre el médico y su paciente proceda la indemnización del daño moral, pero no si esa relación existe, cuando se ha contratado por éste los servicios de aquél ${ }^{31}$.

Ahora bien, la reforma introducida al Código civil por la Ley 171 sobre reparación de daños morales, publicada en el Registro Oficial No. 779 de 4 de julio de 1984, tuvo el propósito de ampliar la protección de los bienes jurídicos extrapatrimoniales, que hasta entonces carecían de reparación. En el considerando segundo de la Ley se lee "[q]ue innumerables actos ilícitos lesionan bienes morales, jurídicamente protegidos, sin embargo de lo cual, en virtud de las actuales normas, quedan sin reparación alguna"; mientras que el considerando tercero reconoce "[q]ue es necesario llenar este vacío legal, incorporando preceptos acordes con las corrientes jurídicas actuales, de las que el Ecuador se halla al margen en este ámbito" ${ }^{\prime 32}$.

Nada hay en estos razonamientos que permita suponer que el legislador buscó proteger solamente afectaciones ocasionadas por un delito o un cuasidelito, dejando de lado aquellas provocadas por el incumplimiento de un contrato, lo que, de ser así, traicionaría su declarado afecto por "las corrientes jurídicas actuales".

La reforma en cuestión incorporó el ahora inciso final del artículo 1572 del Código civil, que quedó con el siguiente texto:

31. Corte Suprema de Justicia de Chile, H. Ruiz Ruiz c. Laboratorio Biológico S.A. y otros, Causa No. 1368-2000. Sentencia, 5/11/2001, Gaceta Jurídica No. 257, 2001.

32. Véase, Ley 171 Reformatoria al Código Civil sobre Reparación de Daños Morales, RO No. 779, 04/06/1984. 
La indemnización de perjuicios comprende el daño emergente y el lucro cesante, ya provengan de no haberse cumplido la obligación, o de haberse cumplido imperfectamente, o de haberse retardado el cumplimiento.

Exceptúanse los casos en que la ley la limita al daño emergente.

Exceptúanse también las indemnizaciones por daño moral determinadas en el Título XXXIII del Libro IV de este Código (énfasis añadido).

Este inciso final es precisamente el motivo de la confusión que se ha producido en torno a la reparabilidad del daño moral en el orden contractual y que tiene como causa una errónea lectura de su texto.

En efecto, se ha dicho que la expresión "Exceptúanse" empleada por el legislador en este inciso final, significa que el daño moral queda excluido (o exceptuado) de la indemnización de perjuicios ocasionados por el incumplimiento de un contrato, que solamente podría comprender el daño emergente y el lucro cesante a los que se refiere el inciso primero del artículo. Y ahí está el error.

Exceptuar es excluir a una persona o cosa de la generalidad de que se trata, de modo que para comprender en que consiste la excepción debe precisarse cuál es la generalidad (o regla general) a la que afecta, que en el caso del artículo 1572 es la proposición inicial: "[1]a indemnización de perjuicios comprende el daño emergente y el lucro cesante". Se advierte que esta proposición contempla las dos modalidades de perjuicios materiales indemnizables: daño emergente y lucro cesante, comunes a toda responsabilidad civil. Pues bien, parece obvio que la norma de exclusión del inciso final alude a que en el caso el daño moral su particular naturaleza impide distinguir esas dos modalidades, lo que en realidad no era necesario decirlo, por la sencilla razón de que son inaplicables al daño moral que no importa un menoscabo del patrimonio. En otras palabras, lo que el legislador hizo con la inclusión del último inciso del artículo 1572 fue resaltar las dife- 
rencias que existen entre los perjuicios materiales y los morales, mas no excluir la posibilidad de que estos últimos puedan repararse en la responsabilidad contractual, pues, a mayor abundamiento, no es esa la dirección de "las corrientes jurídicas actuales" a las que se refirió en los Considerandos de la ley.

El recurso a la historia fidedigna del establecimiento de la ley, a la que se refiere el artículo 18 del Código civil para desentrañar sus pasajes oscuros, conduce a la misma conclusión. Tanto en el informe para primer debate presentado por la Comisión de lo Civil y Penal ${ }^{33}$ como en los considerandos de la ley ${ }^{34}$ se reconoce que existe un sinnúmero de situaciones y actos ilícitos que pueden generar daños morales, y que estos daños deben ser reparados. Para la doctrina jurídica no hay dudas de que el incumplimiento contractual es un hecho ilícito que contraviene no solamente la ley del contrato (artículo 1561 del Código civil) sino los fundamentos mismos del sistema negocial, y que honrar las obligaciones contractuales libremente asumidas no es sólo una legítima aspiración de los contratantes, sino un valor social que se integra al ordenamiento jurídico ${ }^{35}$, razón por la cual puede ser fuente de daños morales que deben indemnizarse.

\subsection{Desarrollo de la jurisprudencia ecuatoriana sobre la repa- ración del daño moral en la responsabilidad contractual}

La jurisprudencia de la ex Corte Suprema de Justicia y de la actual Corte Nacional de Justicia no ha hecho grandes contribuciones teóricas al tema que nos ocupa, aunque muestra una tendencia, si se quiere tímida, hacia la aceptación de la indemnizabilidad del daño moral en la responsabilidad contractual.

33. Cámara Nacional de Representantes, Primer debate del Proyecto de Ley Reformatoria del Código Civil sobre la Reparación de Daños Morales, Acta No. 31, 30/05/1984.

34. Véase, N. 32.

35. Prueba de ello es que el Art. 97 de la Constitución de 1998 contemplaba la necesidad de cumplir los contratos entre los deberes de los ciudadanos. 
La sentencia de 6 de septiembre de 2004 de la Primera Sala de lo Civil y Mercantil de la entonces Corte Suprema de Justicia ${ }^{36}$ comenzó reconociendo que "[1]os contratos tienen una finalidad, persiguen un objetivo, ya sea material o moral". En otras palabras, pueden responder legítimamente a intereses puramente morales, por lo que tal afirmación de la Corte parecía prometedora en el sentido de que la conclusión lógica debía ser que los perjuicios ocasionados por la frustración de estos intereses "morales" debía repararse como daños morales. Sin embargo no fue así y la Corte se limitó a reproducir, sin una argumentación de peso, la doctrina en boga: "[e]l daño se clasifica en material o patrimonial y moral. En la responsabilidad civil contractual, nuestra legislación solo admite el daño material o patrimonial" ${ }^{\prime \prime 3}$. Es decir, recurrió a una petición de principios al dar por sentado lo que debía demostrar en su motivación.

El 8 de septiembre de 2010, la Sala de lo Civil, Mercantil y Familia de la Corte Nacional de Justicia ${ }^{38}$ se decantó por una doctrina radicalmente distinta, admitiendo el daño moral incluso de las personas jurídicas, y dijo:

De tal manera que es acertada la tutela de los derechos extrapatrimoniales inherentes al crédito y buena fama comerciales, porque conducen a su vez a la creación de la confianza en acreedores, relaciones comerciales, proveedores, bancos y público en general, así que no es razón suficiente que estos entes no sean capaces de sufrir dolor, sufrimiento, para suponer que el Derecho no puede proteger los intereses subjetivos o morales de las personas jurídicas. Al contrario, tan necesario es el crédito y el prestigio para el desarrollo de las actividades comerciales como para las personas naturales es el honor y su buen nombre. Por ello, cuando de algún modo injusto se atenta contra el buen crédito y el honor de una persona natural o jurídica, es deber de la Justicia reconocer y declarar el derecho de los perjudicados.- De acuerdo con nuestro orde-

36. Primera Sala de lo Civil y Mercantil de la Corte Suprema de Justicia de Ecuador, Víctor Andrade Carrillo c. Willan Saltos Ledesma, Exp. Cas. 200. Sentencia, 06/09/2004, RO Sup. No. 532, 25/02/2005.

37. Ibídem.

38. Sala de lo Civil, Mercantil y Familia de la Corte Nacional de Justicia, Hotel Boulevard S. A. y Predial Nueve de Octubre S. A. c. Londohotel S. A. y Sociedad Comercial Hoteles Limitada, Exp. Cas. 5082010. Sentencia, 08/09/2010, RO Sup. No. 422, 2/04/2013. 
namiento legal la reparación por daños morales puede ser demandada si tales daños son el resultado próximo de la acción u omisión ilícita del demandado, quedando a la prudencia del Juez la determinación del valor de la indemnización reclamada, atentas las circunstancias previstas en el inciso primero del artículo 2232 del Código Civil. En la especie, es claro que la empresa Londohotel S.A. y su garante solidaria la Sociedad Comercial Hoteles Limitada incumplieron el contrato de administración y operación del Hotel Casino Boulevard, suscrito el 11 de mayo de 1989, por rompimiento unilateral de convenio, y que en la administración del hotel también ha existido dolo; que tal incumplimiento ha causado daños y perjuicios materiales, y perjuicios morales a las empresas demandantes.

No obstante el notable avance teórico de que da cuenta este fallo, se echa de menos nuevamente un análisis exhaustivo de la normativa sobre daño moral en nuestro ordenamiento jurídico.

Finalmente, la sentencia de 7 de agosto de 2015 de la Corte Nacional ${ }^{39}$ aceptó nuevamente la reparación del daño moral como consecuencia del incumplimiento de un contrato de asistencia médica:

Si bien es cierto que es discutible que quepa daño moral en sede de responsabilidad contractual, por la literalidad del artículo 1572, creemos que en este caso dada la naturaleza del contrato de asistencia médica si cabe considerar que del incumplimiento de un contrato entre médico y paciente se produzcan daños morales. La cuantificación de dicho daño moral quedaría al buen criterio del juzgador según el artículo 2232 del Código Civil.

La Sala admite y ordena la reparación del daño moral como consecuencia del incumplimiento contractual, aunque sostiene que esta reparación es "discutible" debido a la literalidad del artículo 1572 del Código civil. Esta posición constituye un progreso, no sólo porque admite la indemnización, sino, lo que parece tanto

39. Sala de lo Civil y Mercantil de la Corte Nacional de Justicia, María Augusta Aguirre Troya c. Bernardo Blum Pinto, Juicio No. 17711-2014-0158, Sentencia, 07/08/2015. 
o más importante, porque califica de discutible la interpretación que se ha dado tradicionalmente al artículo 1572 y abre el camino para la nueva lectura que planeamos como correcta.

\subsection{Desarrollo de laudos nacionales e internacionales sobre la reparación del daño moral en la responsabilidad con- tractual}

La posición favorable a la reparación del daño moral en la esfera contractual también ha sido admitida por tribunales arbitrales, tanto nacionales como internacionales. Si bien los pronunciamientos arbitrales no generan una jurisprudencia vinculante (como sí podría suceder con las sentencias dictadas por la Corte Nacional de Justicia), es importante resaltar la posición de distintos tribunales arbitrales, que no han visto impedimento al momento de declararse competentes para conocer sobre ellos y para admitir que son daños resarcibles. Advertimos que debido a la confidencialidad que rige en estos procedimientos, no podremos hacer referencia a las partes involucradas.

A nivel nacional, en un arbitraje administrado por el Centro de Arbitraje y Conciliación de la Cámara de Comercio de Guayaquil una compañía demandó una indemnización de daño moral por el incumplimiento de la obligación de confidencialidad contenida en un convenio arbitral ${ }^{40}$. El tribunal arbitral, a pesar de desechar la demanda por considerar que la obligación de confidencialidad no fue violada, se declaró competente para conocer la disputa, con lo que tácitamente reconoció que la disputa y sus pretensiones (la indemnización de daño moral) cumplen con los requisitos de la arbitrabilidad objetiva previstos por la Ley de Arbitraje y Mediación.

A nivel internacional, en un arbitraje administrado por la Comisión Interamericana de Arbitraje Comercial ${ }^{41}$ se discutió tanto

40. Centro de Arbitraje y Conciliación de la Cámara de Comercio de Guayaquil, Proceso No. 045-13, 17/09/2014.

41. Comisión Interamericana de Arbitraje Comercial, Partes confidenciales, Caso No. $50181 \mathrm{~T} 0041306$. Laudo final, 5/05/2010. 
la arbitrabilidad del daño moral como la posibilidad de resarcirlo en sede de responsabilidad contractual, según el derecho ecuatoriano, y el Tribunal consideró:

398. De este modo, si el daño moral constituye una forma de perjuicio sufrido por la infracción de un contrato que como se expuso puede reclamarse a través de las acciones contractuales, debe entonces concluir el Tribunal que el mismo es competente para determinar si el incumplimiento del Contrato celebrado entre las partes causó daños morales al demandante que deban ser resarcidos por el demandado. A este respecto no sobra reiterar que el numeral 26.1 de las Condiciones Generales del Contrato (CGC) prevé los mecanismos de resolución de conflictos para los "desacuerdos o conflictos que surjan entre ellos en virtud de o en relación el Contrato," sin excluir ningún tipo de daño.

\section{Arbitrabilidad del daño moral en materia de RESPONSABILIDAD EXTRACONTRACTUAL}

Contrariamente a lo que sucede con la responsabilidad contractual, no se discute la posibilidad de que se indemnicen los daños morales ocasionados por un delito o cuasidelito, pues justamente el inciso final de artículo 1572 se refiere expresamente a esa indemnización.

Siendo así no hay obstáculo legal alguno para que su reparación pueda ser materia de arbitraje, y así lo señala el artículo 5 de la Ley de Arbitraje y Mediación que al definir el convenio arbitral se refiere a las controversias que puedan surgir de relaciones jurídicas contractuales o no contractuales, y luego contempla una exigencia particular para los casos de indemnizaciones por delitos y cuasidelitos: "[e]n los demás casos, es decir, de convenios arbitrales sobre las indemnizaciones civiles por delitos o cuasidelitos, el convenio arbitral deberá referirse a los hechos sobre los que versará el arbitraje". 
Lo que parece claro, además, del texto transcrito, es que tratándose de esta modalidad de responsabilidad normalmente el arbitraje sólo podrá tener lugar una vez producida la controversia pues solamente entonces pueden conocerse "los hechos sobre los que versará el arbitraje" y satisfacerse, de esa manera, la exigencia del artículo 5; salvo que se trate de materias en las que, por su naturaleza y experiencia práctica, las partes puedan prever eventuales daños aquilianos, como es el caso de los contratos de prestación de servicios médicos o de construcción en los que una cláusula arbitral podría identificarlos a priori.

\section{Conclusión}

La arbitrabilidad objetiva es uno de los temas más importantes que los tribunales arbitrales deben analizar al momento de examinar su competencia. En el caso de la Ley de Arbitraje y Mediación ecuatoriana, el principal requisito para que un asunto sea susceptible de arbitraje es que se trate de materia transigible.

Hemos demostrado que el daño moral es una materia transigible. Si bien por lo general se asimila la materia transigible con aquellos bienes jurídicos de naturaleza patrimonial, esta visión es reductora, pues lo que constituye la esencia de la transigibilidad es que su objeto afecte únicamente el interés privado de quienes celebran el contrato. De esta manera si se ha lesionado un bien jurídico extrapatrimonial o moral que mire solamente al interés privado, esa lesión será susceptible de transacción, y por ende resultará arbitrable. A mayor abundamiento, el legislador ecuatoriano ha optado por el resarcimiento pecuniario del daño moral, lo que robustece la idea de su transigibilidad.

El punto más discutido, tanto en la jurisdicción arbitral como en la ordinaria, dice relación con la posibilidad de indemnizar el daño moral provocado por el incumplimiento contractual. La doctrina jurídica moderna se orienta progresivamente en favor de esa indemnización y creemos que esa debe ser la posición en 
nuestro ordenamiento civil, tanto por la norma del artículo 1572 del Código civil, entendida en su exacto sentido, como por la incipiente jurisprudencia que existe sobre este punto y el principio de la reparación integral daño que constituye uno de los pilares de la responsabilidad civil. Como corolario de todo aquello, y con el fundamento textual del artículo 5 de la Ley de Arbitraje y Mediación, debe afirmarse la arbitrabilidad de las controversias que tienen por objeto la reparación del daño moral en sede contractual. 